\title{
Epidemiology, genetic variants and clinical course of natural infections with Anaplasma phagocytophilum in a dairy cattle herd
}

\author{
Cornelia Silaghi ${ }^{1,2 \dagger}{ }^{+}$Marion Nieder $^{3 \dagger}$, Carola Sauter-Louis ${ }^{4,5}$, Gabriela Knubben-Schweizer ${ }^{4}$, Kurt Pfister ${ }^{1}$
} and Martin Pfeffer ${ }^{3^{*}}$

\begin{abstract}
Background: Anaplasma phagocytophilum is an obligate intracellular, tick-transmitted bacterium that causes granulocytic anaplasmosis in humans and several mammalian species including domestic ruminants where it is called tick-borne fever (TBF). Different genetic variants exist but their impact with regard to putative differences in host associations and pathogenicity are not yet completely understood.

Methods: Natural infections with A. phagocytophilum in a dairy cattle herd in Germany were investigated over one pasture season by using serology, haematology, blood chemistry and polymerase chain reaction (PCR). Sequence analysis of partial 165 rRNA, groEL, msp2 and msp4 genes of A. phagocytophilum was carried out in order to trace possible genetic variants and their relations between cattle, roe deer (Capreolus capreolus) and ticks (Ixodes ricinus) in this area.

Results: In total 533 samples from 58 cattle, 310 ticks, three roe deer and one wild boar were examined. Our results show (i) typical clinical symptoms of TBF in first-time infected heifers, such as high fever, reduced milk yield, lower limb oedema and typical haematological and biochemical findings such as severe leukopenia, erythropenia, neutropenia, lymphocytopenia, monocytopenia, a significant increase in creatinine and bilirubin and a significant decrease in serum albumin, $y-G T, G L D H$, magnesium and calcium; (ii) a high overall prevalence of $A$. phagocytophilum infections in this herd as 78.9\% (15/19) of the naïve heifers were real-time PCR-positive and 75.9\% (44/58) of the entire herd seroconverted; and (iii) a high level of sequence variation in the analysed genes with five variants of the 16S rRNA gene, two variants of the groEL gene, three variants of the msp2 gene and four variants in the msp4 gene with certain combinations of these variants.

Conclusions: In cattle particular combinations of the genetic variants of A. phagocytophilum occurred, whereas three roe deer showed different variants altogether. This is indicative for a sympatric circulation of variants in this small geographical region $\left(<1 \mathrm{~km}^{2}\right)$. Both re- and superinfections with A. phagocytophilum were observed in five cattle showing that infection does not result in sterile immunity. For prevention of clinical cases we suggest pasturing of young, not pregnant heifers to reduce economical losses.
\end{abstract}

Keywords: Anaplasma phagocytophilum, Cattle, Tick-borne fever, Ixodes ricinus, 165 rRNA gene, groEL gene, msp2 gene, msp4 gene, Germany

\footnotetext{
* Correspondence: pfeffer@vetmed.uni-leipzig.de

${ }^{\dagger}$ Equal contributors

${ }^{3}$ Institute for Animal Hygiene and Veterinary Public Health, Faculty of

Veterinary Medicine, University of Leipzig, Leipzig, Germany

Full list of author information is available at the end of the article
} 


\section{Background}

The tick-transmitted obligate intracellular, gram-negative bacterium Anaplasma phagocytophilum occurs in intracytoplasmatic vacuoles in neutrophilic and eosinophilic granulocytes of infected mammalian hosts [1]. In Europe, the main vector is the hard tick Ixodes ricinus and the main reservoir hosts discussed are roe deer (Capreolus capreolus) and other wildlife ruminants, but also wild boars (Sus scrofa), hedgehogs (Erinaceinae) and other small mammal species [2]. Anaplasma phagocytophilum causes granulocytic anaplasmosis in humans, horses, dogs and cats and tick-borne fever (TBF) in ruminants [3]. Typical clinical signs of TBF include fever, sudden decrease in milk production, inappetence, lethargy, lower limb oedema; typical laboratory observations are leukopenia and thrombocytopenia [4-7]. TBF causes economical losses due to the drastic decrease in milk production and is considered to be underdiagnosed in cattle $[4,6,8]$. Only few reports on natural infections on herd basis exist. They all describe two peaks of clinical cases in spring and autumn, matching the highest activity levels of $I$. ricinus ticks [6, 9-13]. A high genetic variation of A. phagocytophilum was described previously for several partial gene fragments [14]. Different $A$. phagocytophilum strains seem to have varying infectivity for different mammalian species [1]. Multilocus sequence typing (MLST) showed that the population structure of $A$. phagocytophilum might be semiclonal with a uniform clonal complex 1 with strains from humans, dogs and horses and a higher heterogeneity in clonal complex 2 with strains from wild and domestic ruminants [2]. In Germany, the first laboratory confirmed case of TBF occurred in 2010 in a dairy cattle herd in North-Rhine-Westphalia [8]. This study presents the follow-up diagnosis in the same herd. The objectives were to identify natural infections with $A$. phagocytophilum in a dairy cattle herd by cytology, serology, haematology, blood chemistry and polymerase chain reaction (PCR) as well as genetic variants of the partial $16 S$ rRNA, groEL (heat-shock protein HSP60, also known as caperonin 60), msp2 and msp4 (major surface proteins 2 and 4) genes. The results will allow to determine associations between cattle, wild animals and ticks in the area under investigation and to identify effective control measures.

\section{Methods}

\section{Dairy cattle herd}

This study was performed from April 2011 to February 2012 in a dairy cattle herd in North-Rhine-Westphalia, Germany, where tick-borne fever is endemic [8]. The minimal stock was 39 cows and 11 heifers (in this paper heifer is used synonymous for first calf heifer) in May 2011 and the maximal stock was 39 cows and 19 heifers in July 2011. The animals were cross-breeds of Red and
Black Holstein Friesian and German Simmental in a closed breeding system. The herd went to pasture from May 9th until October 27th during daytime hours between milking times and stayed in a freestall barn overnight and during the winter months. Cows were pastured in turns on four different 2.5 ha to 4.0 ha pastures from $250 \mathrm{~m}$ to $400 \mathrm{~m}$ above sea level. Pastures were surrounded by small forests, contained watering places and were often frequented by wild animals like roe deer and wild boars, but not by red deer (Cervus elaphus). Heifers went to the pasture for the first time, whereas the cows had been to the pastures for one or more pasture periods before. Tick infestation on the animals was regularly observed during milking times. Eight of the 19 heifers (nos. 7, 15, 16, 23, 28, 52, 53, 61) were treated by the farmer with repellents (flumethrin: Bayti$\mathrm{col}^{\odot}$ Pour-on, $10 \mathrm{mg} / \mathrm{ml}$, Bayer AG, Germany) according to the product information every 3 weeks from May 15th until they calved. Effectiveness against ticks is stated with 3 weeks, the withholding period on meat is 5 days and on milk 8 days. Therefore, treatment of heifers was stopped when they calved and lactating cows had not been treated with repellents at all.

\section{Clinical examination and blood sampling}

Blood samples of the herd were taken prior to pasturing in May 2011 and then every other month until January 2012 ("herd screening"). Cytological, serological and PCR examinations were performed as described below. Previous cases of TBF in the herd showed that clinical infections with $A$. phagocytophilum become most obvious in lactating naïve heifers [8]. Therefore, rectal body temperature was measured daily in heifers and a body temperature $\geq 39.5{ }^{\circ} \mathrm{C}$ was considered suspicious for an infection. Subsequently, these heifers were observed by the farmer for reduced milk yield, discharge from eyes and nose, lower limb oedema and stiff walking. Blood was taken for detection of $A$. phagocytophilum and in case of positive PCR results, additional blood samples were taken weekly for the following 6-8 weeks and thereafter every other week for further 6-8 weeks (Fig. 1). All blood samples for diagnostic purposes were taken from tail veins into EDTA- and serum-tubes (S-Monovette, $10 \mathrm{ml}$, Sarstedt AG \& Co, Nümbrecht, Germany).

Cytological, serological, haematological and biochemical examination

Buffy coat smears were prepared from every sample and stained with Giemsa for microscopical investigations for morulae of $A$. phagocytophilum. Serum samples were analysed for $A$. phagocytophilum antibodies by indirect immunofluorescence (IFAT) with the MegaScreen ${ }^{\circ}$ Fluoanaplasma ph. slides (MegaCor, Hörbranz, Austria) 


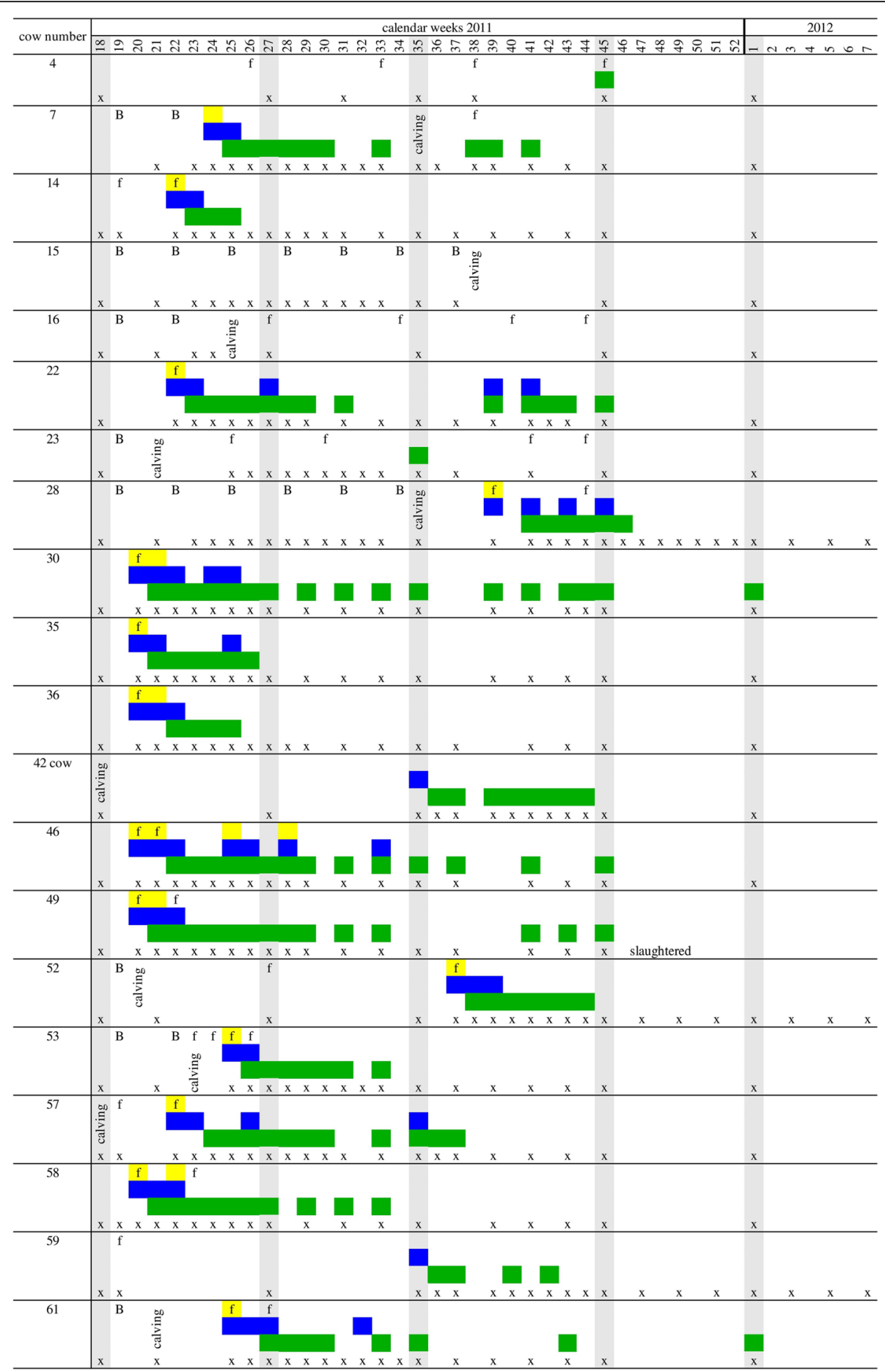

Fig. 1 Course of infection of observed heifers and cows in the herd in relation to clinical, microscopial and serological findings. Yellow, morulae in buffy coat smears; blue, real-time PCR-positive for A. phagocytophilum; green, positive titer >1:100; grey, herd screening; $f$, fever; $B$, Bayticol ${ }^{\circledR}$-treatment; $x$, sampling point

and anti-bovine IgG-conjugate in a dilution of 1:80 (Sigma-Aldrich, Taufkirchen, Germany). A serum titer starting from 1:100 was considered positive whereas 1:50 was considered as borderline titer. Blood of A. phagocytophilum-positive heifers was also examined for haematological and biochemical parameters. EDTAblood was used for determination of leukocytes, erythrocytes, thrombocytes, hematocrit, haemoglobin and a differential blood count. Urea nitrogen, creatinine, total protein, albumin, total bilirubin, phosphor, magnesium, 
calcium, sodium, potassium, chloride and the activities of aspartate aminotransferase (AST), $\gamma$-glutamyltransferase $(\gamma-\mathrm{GT})$, glutamate dehydrogenase $(\mathrm{GLDH})$ and creatine kinase (CK) was measured in the serum. The examinations were performed according to the laboratory's standard (Clinic for Ruminants with Ambulatory and Herd Health Services, Faculty of Veterinary Medicine, LudwigMaximilians-University Munich). For the statistical analysis (see below) of the blood parameters samples from day 0 (day of clinical signs in combination with first realtime PCR positive result), day 7, day 14, day 21 and day 28 were compared with samples from day 200 after first realtime PCR positive result.

\section{Environmental investigations}

For detection of prevalence and different genetic variants of $A$. phagocytophilum in the pasture area, ticks and professionally hunted wild animals were examined as follows: Ticks were collected on 5 days from April to June 2011 on four pastures in areas containing bushes and trees by the flagging method. Additionally, engorged ticks were collected from cows during milking time and from professionally hunted game animals from the pasture area in May and June 2011. Ticks were stored in $70 \%$ ethanol for individual identification to species level under a stereomicroscope [15] and were separated by sex, stage and date of collection. For DNA-extraction and PCR all adults were examined separately whereas nymphs and larvae were pooled with a maximum of five individuals in a tube. Spleen tissue samples from game animals were taken with a sterile punch and stored in $70 \%$ ethanol for further analysis.

\section{DNA extraction and real-time PCR}

DNA extraction of blood and spleen samples was accomplished with Maxwell ${ }^{\bullet} 16$ LEV Blood DNA Kit (Promega, Madison, USA) according to the manufacturer's instructions in Maxwell $^{\circ} 16 \mathrm{MDx}$ (Promega, Madison, USA). DNA extraction of ticks was performed with QIAmp DNA Mini Kit (Quiagen, Hilden, Germany) according to the manufacturer's instructions with modifications. Ticks were macerated individually with $0.6 \mathrm{~g}$ ceramic beads with $1.4 \mathrm{~mm}$ diameter (peqLab) and $100 \mu \mathrm{l}$ PBS-Buffer at 5000x rpm for $5 \mathrm{~min}$ in a tissue homogenizer (Precellys ${ }^{\circ} 24$, Bertin technologies, Montigny-le-Bretonneux, France), kept overnight at $56{ }^{\circ} \mathrm{C}$ with $100 \mu \mathrm{l}$ ATL-Buffer and $20 \mu \mathrm{l}$ Proteinase $K$. Final eluation was done with $50 \mu \mathrm{l} \mathrm{AE-Buffer.} \mathrm{Extracted}$ DNA was tested for quality and quantity with a spectrophotometer (NanoDrop ${ }^{\circ}$ ND-1000, PeqLab, Erlangen, Germany). Blood and spleen samples were screened for $A$. phagocytophilum with real-time PCR targeting the msp 2 gene [16, 17]. All samples were tested in duplicates along with positive and negative controls (see
Additional file 1: Table S1 for all cycling conditions and primers used).

\section{PCR genotyping and sequence analysis}

PCR genotyping and sequence analysis was performed for the first real-time PCR-positive sample of a cow or a heifer and for positive samples of roe deer and ticks. To detect possible new infections with different genetic variants, further samples from certain positive heifers were additionally tested. Investigations included a nested-PCR targeting a 497 bp part of the $16 S$ rRNA gene of $A$. phagocytophilum [18], a heminested PCR assay for a $530 \mathrm{bp}$ part of the groEL gene [19], a conventional PCR targeting a $893 \mathrm{bp}$ part of the $m s p 2$ gene [20] and a nested PCR of a 350 bp msp 4 gene [21, 22]. PCRs were performed according to Silaghi et al. [23] (Additional file 1: Table S1). Amplicons were visualized using UV light after staining with GelRed $^{\circ}$ (Biotium, Hayward, USA) and 2.0\% agarose gel electrophoresis and purified with QIAquick PCR Purification Kit according to the manufacturer's instructions (Qiagen, Hilden, Germany). Sequencing with forward and reverse primers of the nested reactions was performed by Eurofins MWG Operon (Martinsried, Germany). The obtained sequences were analysed with: Chromas@Lite (http://technelysium.com.au), BLASTn (http://blast.ncbi.nlm.nih.gov/Blast.cgi under "nucleotide blast"), Reverse Complement (http:// www.bioinformatics.org/sms/rev_comp.html) and ClustalW2 (http://www.ebi.ac.uk/Tools/msa/clustalw2/) [24].

\section{Statistical analysis}

Data were examined visually for normal distribution using box-and-whisker plots. The calculation of means, medians and standard deviations (SDs) was done using SPSS (IBM, version 21). Concentrations of different blood parameters were compared using Wilcoxon signed-rank test for paired samples, whereby the concentrations of different days during the period of infection were compared with the concentrations at day 200, which was outside the period of infection. A $P$-value of less than 0.01 was considered statistically significant.

\section{Results}

In total 15 out of the 19 heifers (78.9\%) and one out of the 39 cows (2.6\%) were positive in real-time PCR for $A$. phagocytophilum during the pasture period. This corresponds to an overall prevalence of $27.6 \%$ for the whole herd.

\section{Clinical picture}

All A. phagocytophilum-positive heifers except for two showed typical clinical symptoms of TBF at first infection (Table 1). One cow (no. 42) and one heifer (no. 7) were not examined for clinical symptoms before their 
Table 1 Analysed sequences of A. phagocytophilum in this herd in combination with clinical symptoms of the infected animals

\begin{tabular}{|c|c|c|c|c|c|c|c|}
\hline Cow no./ tick no./roe deer no. & Date of positive PCR & Ct-value & Clinic & $16 S$ rRNA & groEL & msp2 & msp4 \\
\hline 7 & 19.06.11 & 23 & not examined & $16 \mathrm{~S}-20(\mathrm{~W})$ & g-18 (X) & M2-26 & M4-49 \\
\hline 14 & 04.06 .11 & 17 & $\mathrm{~F}, \mathrm{RM}$ & $16 S-20(W)$ & g-18 (X) & M2-26 & M4-49 \\
\hline \multirow[t]{3}{*}{22} & 30.05 .11 & 15 & F, RM, LLO & $16 S-20(W)$ & g-18 (X) & M2-26 & M4-49 \\
\hline & 09.07 .11 & 28.5 & no clinic & $16 S-20(\mathrm{~W})$ & too short & negative & M4-50 \\
\hline & 03.10 .11 & 28 & no clinic & $16 \mathrm{~S}-20(\mathrm{~W})$ & $\mathrm{g}-15(\mathrm{~N})$ & negative & M4-51 \\
\hline 28 & 03.10 .11 & 20 & $F, R M, D C$ & $16 S-20(W)$ & $g-15(N)$ & negative & $M 4-51$ \\
\hline 30 & 17.05 .11 & 27.5 & $F, R M, D C$ & $16 \mathrm{~S}-20(\mathrm{~W})$ & $g-18(X)$ & too short & M4-50 \\
\hline 35 & 17.05 .11 & 15 & $\mathrm{~F}, \mathrm{RM}$ & $16 \mathrm{~S}-20(\mathrm{~W})$ & $g-18(X)$ & M2-26 & M4-49 \\
\hline 36 & 19.05.11 & 13.5 & $F, R M, D C$ & $16 \mathrm{~S}-20(\mathrm{~W})$ & too short & M2-26 & M4-49 \\
\hline 42 & 04.09 .11 & 36 & not examined & $16 \mathrm{~S}-20(\mathrm{~W})$ & too short & negative & M4-49 \\
\hline \multirow[t]{2}{*}{46} & 22.05 .11 & 19.5 & F, RM, DC, LLO & $16 \mathrm{~S}-20(\mathrm{~W})$ & g-18 (X) & M2-26 & M4-49 \\
\hline & 21.08 .11 & 30 & no clinic & negative & negative & negative & M4-50 \\
\hline 49 & 19.05.11 & 31.5 & F, RM, DC, LLO & $16 \mathrm{~S}-20(\mathrm{~W})$ & $g-15(N)$ & negative & M4-51 \\
\hline 52 & 14.09 .11 & 19.5 & F, RM, LLO & $16 \mathrm{~S}-20(\mathrm{~W})$ & too short & M2-27 & M4-51 \\
\hline 53 & 22.06 .11 & 14 & $\mathrm{~F}, \mathrm{RM}, \mathrm{DC}$ & $16 \mathrm{~S}-20(\mathrm{~W})$ & $g-18(X)$ & negative & M4-49 \\
\hline \multirow[t]{2}{*}{57} & 04.06 .11 & 18.5 & $\mathrm{~F}, \mathrm{RM}, \mathrm{DC}$ & $16 \mathrm{~S}-20(\mathrm{~W})$ & $g-18(X)$ & M2-26 & M4-49 \\
\hline & 04.09.11 & 30 & no clinic & $16 S-20(\mathrm{~W})$ & negative & negative & M4-49 \\
\hline \multirow[t]{2}{*}{58} & 17.05 .11 & 24.5 & $\mathrm{~F}, \mathrm{RM}, \mathrm{DC}$ & $16 \mathrm{~S}-20(\mathrm{~W})$ & g-18 (X) & M2-26 & M4-49 \\
\hline & 09.07.11 & 31 & no clinic & $16 \mathrm{~S}-20(\mathrm{~W})$ & negative & negative & negative \\
\hline 59 & 04.09 .11 & 26.5 & no clinic & $16 S-22(Y)$ & too short & negative & M4-13 (n) \\
\hline \multirow[t]{2}{*}{61} & 22.06 .11 & 18 & F, RM, DC, LLO & $16 \mathrm{~S}-20(\mathrm{~W})$ & g-18 (X) & M2-26 & M4-49 \\
\hline & 09.07.11 & 22 & no clinic & $16 \mathrm{~S}-20(\mathrm{~W})$ & negative & M2-27 & M4-51 \\
\hline Tick $83^{\mathrm{a}}$ & 13.05 .11 & 29 & & 16S-7 (I) & negative & negative & negative \\
\hline Tick $90^{\mathrm{b}}$ & 06.06 .11 & 20 & & $16 S-20(W)$ & too short & negative & M4-51 \\
\hline Tick $94^{\mathrm{b}}$ & 06.06 .11 & 23 & & $16 \mathrm{~S}-20(\mathrm{~W})$ & too short & negative & M4-49 \\
\hline Tick $96^{\mathrm{b}}$ & 06.06 .11 & 19 & & $16 S-20(W)$ & too short & negative & M4-51 \\
\hline Tick $167^{a}$ & 25.06 .11 & 30 & & $16 S-22(Y)$ & too short & negative & M4-13 (n) \\
\hline Roe deer 1 & 26.06 .11 & 30 & & $16 S-21(X)$ & negative & M2-9 (J) & too short \\
\hline Roe deer 2 & 17.09 .11 & 27.5 & & $16 S-21(X)$ & negative & negative & negative \\
\hline Roe deer 3 & 15.10 .11 & 30 & & 16S-19 (V)-like sequence & too short & negative & too short \\
\hline
\end{tabular}

Abbreviations: $F$ fever, $R M$ reduced milk yield, $D C$ discharge from eyes and nose, $L L O$ lower limb oedema and stiff walking

Note: Nomenclature of gene variants is following previous denominations $[17,23,25]$ with numbers after the gene abbreviation. The letter codes shown for some of these variants are an alternative, also unofficial nomenclature. Particular combinations of these four gene variants were frequently observed with $16 \mathrm{~S}$-20 (W), $\mathrm{g}$ $18(\mathrm{X}), \mathrm{M} 2-26$, and M4-49 are given in bold; negative = gene locus could not be amplified; too short = gene locus was amplified but the sequence read was too short for full comparison and thus for allocation to a particular variant. Ct-values are provided as mean of two independent real-time PCRs targeting the msp2gene, which was used for screening. Please note that tick screening was done only once. A ct-value $\leq 38$ was considered positive for $A$. phagocytophilum DNA

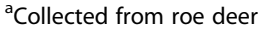

${ }^{\mathrm{b}}$ Collected from heifer

positive results and one heifer (no. 59) showed no clinical symptoms at all (Fig. 1). Six heifers developed clinical symptoms after 8-13 days of first exposure to the tickinfested area in May, five heifers after 21-44 days in June. Only two heifers (nos. 28 and 52) developed TBF in autumn and one of them was brought for the first time to the pasture in September. Thirteen out of the 16 animals that were real-time PCR-positive for A. phagocytophilum had one to 5 days fever before their first real-time PCR positive result. The mean rectal body temperature in the period of fever was $40.5{ }^{\circ} \mathrm{C}$ (range: $39.5-41.7^{\circ} \mathrm{C}$ ). All 13 heifers showed a sudden decrease in milk production, nine had discharge from eyes and nose and five showed lower limb oedema and stiff walking (Table 1). Fourteen out of the 16 real-time PCR-positive animals had more than one sample with a positive real-time PCR result (Fig. 1). Seven heifers (nos. 22, 28, 30, 35, 46, 57, 61) had positive samples after at least 1 week of a negative result and they showed no clinical signs at this time. All affected animals recovered without antibiotic treatment after an average duration of 1 week. 


\section{Cytological, serological, haematological and biochemical examination}

In total, 533 EDTA and 533 serum samples were taken. Morulae could be observed in leukocytes in every first real-time PCR-positive sample of the heifers except for the two animals that where found positive in the herd screening (nos. 42, 59, see above). They could be seen in the first sample $(n=14)$ on the day of fever or also in the second sample $(n=4)$ 1 week later. Morulae were always found in samples of heifers with clinical symptoms and positive realtime PCR. In real-time PCR-positive samples, when the heifers did not show any clinical signs, morulae could only be observed in two heifers (nos. 46, 58) (Fig. 1). In total $75.9 \%$ of the herd (44/58 animals) showed antibodies over the whole pasture season and $44.8 \%$ (26/58 animals) had positive titers of $\geq 1: 100$ (Table 2). Seroprevalence with titers of $\geq 1: 100$ was $0.0 \%$ prior to pasturing in May 2011 and increased to a maximum of $36.2 \%$ in July. In September seroprevalence decreased to $27.3 \%$, in November to $17.9 \%$ and was $3.8 \%$ in January 2012 (Additional file 2: Figure S1). The highest titers (up to 1:6400) occurred in July 2011, parallel to the seroprevalence peak (Table 2, Additional file 2: Figure S1). Antibodies were always observed 1 week after the first PCR-positive result for A. phagocytophilum and lasted from 2 weeks (nos. 42, 59) up to nine consecutive weeks (no. 49) (Fig. 1). Some animals (nos. 30, 49, 58) may have even longer lasting antibody titres, but as we shifted the sampling intervals to 2 weeks, we cannot rule out a re- or superinfection in between. (Fig. 1). In haematological and biochemical examinations (Table 3) we found a significant leukopenia, erythropenia, neutropenia (only segmented neutrophils), lymphocytopenia and monocytopenia in animals with positive real-time PCR results (day 0) versus animals with negative real-time PCR results (day 200). We also found a significant increase in the parameters creatinine and bilirubin and a significant decrease in the parameters albumin, $\gamma$ GT, GLDH, magnesium and calcium between animals at these time points (Table 3).

\section{Environmental investigations}

In total 310 ticks, three professionally hunted roe deer and one wild boar were examined. Altogether 209 questing ticks (79 adults, 123 nymphs and 7 larvae), 74 engorged ticks from cows and 27 engorged ticks from two hunted roe deer were collected. All were identified as $I$. ricinus. Out of the questing ticks $1.9 \%$ (three adults and a pooled sample of 5 nymphs) were PCR-positive for A. phagocytophilum. The collected engorged ticks were all adults and 14 out of 74 (18.9\%) engorged ticks from cows and 8 out of 27 (29.6\%) engorged ticks from two roe deer were PCR-positive for A. phagocytophilum. The spleen tissue samples from roe deer were all $(3 / 3)$ PCR-positive for $A$. phagocytophilum, while the spleen sample from the wild boar was negative.

\section{Bayticol $^{\circledR}$ treatment}

Bayticol $^{\odot}$ has a withholding period of 8 days for milk in Germany. Consequently the treatment was stopped immediately after calving of the heifers. Seven out of eight treated heifers stayed uninfected with A. phagocytophilum during the treatment and only on animal (no. 7) became positive while treated with Bayticol $^{\circ}, 2$ weeks after the second treatment. Two animals (nos. 15, 16) did not become positive in the entire period of observation after seven or two rounds of Bayticol ${ }^{\circledR}$ treatment before they calved. The remaining five heifers were either real time PCR-positive for A. phagocytophilum in the following three to 18 weeks (nos. 28, 52, 53, 61) or showed antibodies against $A$. phagocytophilum 13 weeks after calving, which was the time when the Bayticol $^{\circledR}$ ended (Fig. 1).

\section{Gene sequences}

The sequences from this study are available in GenBank under the accession numbers KU587048KU587126. Table 4 shows the nucleotide differences and Table 1 the distribution of the different variants for the four partial gene sequences in the herd. Comparison to the most identical gene sequences in GenBank is provided in Additional file 3: Table S2. Nomenclature of the found variants is not official,

Table 2 Serum titers of IgG against A. phagocytophilum in a dairy cattle herd (heifers and cows) from May 2011 to January 2012

\begin{tabular}{|c|c|c|c|c|c|c|c|c|c|c|}
\hline \multirow[t]{2}{*}{ Month } & \multirow[t]{2}{*}{ Total no. of cows ${ }^{a}$} & \multicolumn{9}{|l|}{ Titers } \\
\hline & & 0 & $1: 50$ & $1: 100$ & $1: 200$ & $1: 400$ & $1: 800$ & $1: 1600$ & $1: 3200$ & 1:6400 \\
\hline May & $50(39,11)$ & $48(37,11)$ & $2(2,0)$ & 0 & 0 & 0 & 0 & 0 & 0 & 0 \\
\hline July & $58(39,19)$ & $29(20,9)$ & $8(7,1)$ & $7(5,1)$ & $8(3,5)$ & $1(0,1)$ & 0 & $2(1,1)$ & $2(2,0)$ & $1(1,0)$ \\
\hline September & $55(36,19)$ & $30(19,11)$ & $10(7,3)$ & $11(7,4)$ & $3(3,0)$ & $1(0,1)$ & 0 & 0 & 0 & 0 \\
\hline November & $56(37,19)$ & $33(21,12)$ & $13(8,5)$ & $7(3,4)$ & 0 & 0 & $3(2,1)$ & 0 & 0 & 0 \\
\hline January & $52(34,18)$ & $40(25,15)$ & $10(9,1)$ & $1(0,1)$ & $1(0,1)$ & 0 & 0 & 0 & 0 & 0 \\
\hline
\end{tabular}

${ }^{a}$ Numbers of cows and heifers, in that order, are indicated in parentheses 


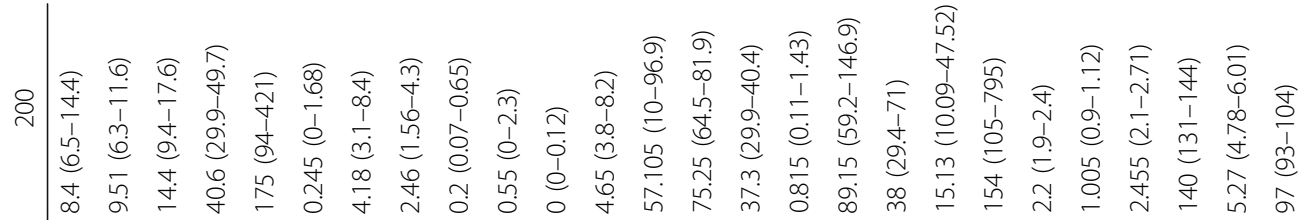

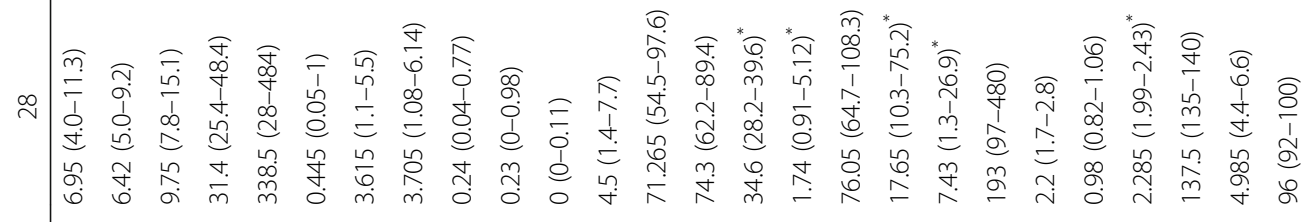

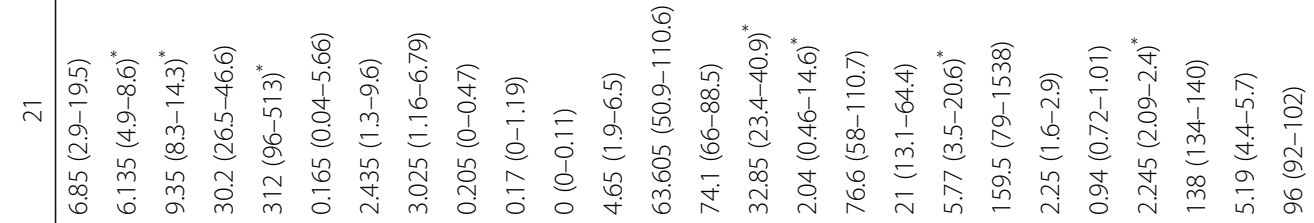

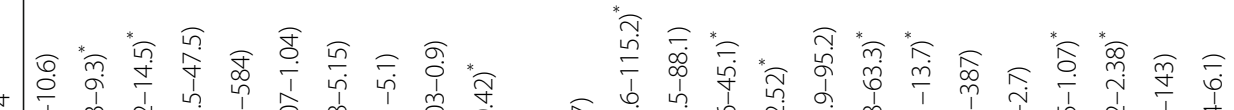

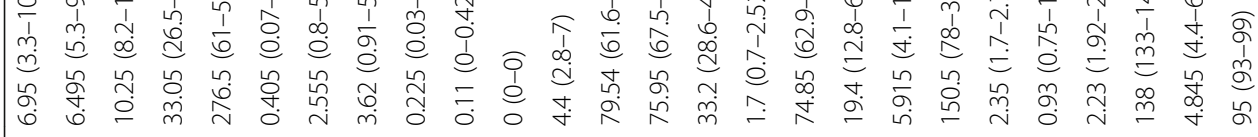

$$
\text { s. }
$$

非

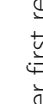

$$
\text { 离 }
$$$$
\stackrel{5}{\frac{\pi}{4}}
$$

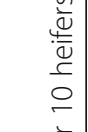$$
\text { . }
$$

郭

\section{รุ}

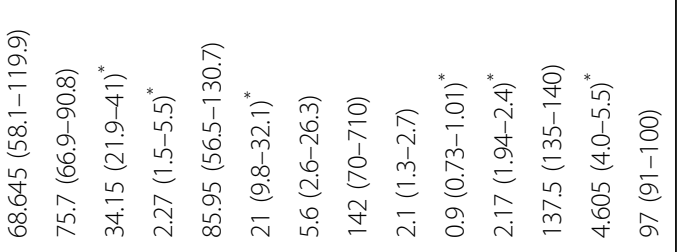

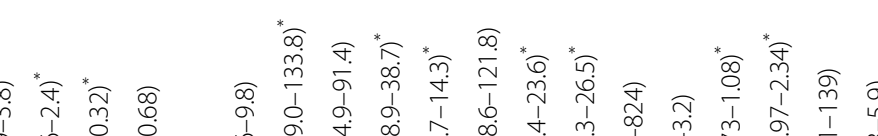

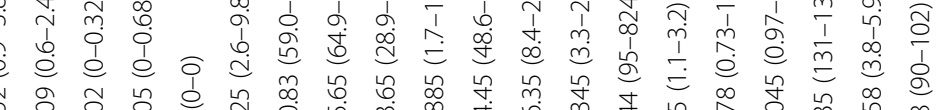


Table 4 Nucleotide differences of Anaplasma phagocytophilum in the amplified partial genes

\begin{tabular}{|c|c|c|c|c|c|c|c|c|c|c|c|c|c|c|c|}
\hline \multirow[t]{2}{*}{ Gene } & \multirow[t]{2}{*}{ Variant $^{\mathrm{e}}$} & \multirow[t]{2}{*}{ Host $(n)$} & \multicolumn{13}{|c|}{ Nucleotide position } \\
\hline & & & 76 & 80 & 84 & 175 & 237 & & & & & & & & \\
\hline $16 S r R N A^{a}$ & 16S-7 (I) & tick (1) & G & $A$ & A & A & G & & & & & & & & \\
\hline \multirow[t]{5}{*}{ (497 bp) } & 16S-19 (V)-like & roe deer (1) & A & G & A & C & A & & & & & & & & \\
\hline & $16 S-20(W)$ & $\operatorname{cow}(20)$, ticks (3) & $A$ & A & A & C & G & & & & & & & & \\
\hline & $16 S-21(X)$ & roe deer (2) & G & A & $A$ & C & G & & & & & & & & \\
\hline & $16 \mathrm{~S}-22(\mathrm{Y})$ & cow (1), ticks (1) & G & A & G & C & G & & & & & & & & \\
\hline & & & 780 & 840 & & & & & & & & & & & \\
\hline $\operatorname{groEL}^{\mathrm{b}}$ & g-15 (N) & $\operatorname{cow}(3)$ & A & $\mathrm{T}$ & & & & & & & & & & & \\
\hline \multirow[t]{2}{*}{ (530 bp) } & g-18 (X) & cow (10) & G & C & & & & & & & & & & & \\
\hline & & & 249 & 265 & 291 & & & & & & & & & & \\
\hline$m s p 2^{c}$ & m2-9 (J) & roe deer (1) & T & C & $\mathrm{T}$ & \multicolumn{10}{|c|}{ further 45 nucleotide differences to m2-26 and m2-27 } \\
\hline \multirow[t]{3}{*}{ (893 bp) } & $m 2-26$ & $\operatorname{cow}(9)$ & T & A & A & & & & & & & & & & \\
\hline & $m 2-27$ & $\operatorname{cow}(2)$ & A & C & G & & & & & & & & & & \\
\hline & & & 375 & 390 & 405 & 411 & 427 & 450 & 462 & 510 & 516 & 603 & 612 & 672 & 678 \\
\hline$m s p 4^{d}$ & $\mathrm{~m} 4-13(n)$ & cow (1), tick (1) & G & G & $\mathrm{T}$ & G & A & T & $\mathrm{T}$ & C & C & T & $\mathrm{C}$ & A & C \\
\hline \multirow[t]{3}{*}{ (343 bp) } & m4-49 & cow (12), tick (1) & T & A & C & A & G & T & C & C & $\mathrm{T}$ & C & $\mathrm{T}$ & A & C \\
\hline & m4-50 & $\operatorname{cow}(3)$ & T & A & C & A & G & C & C & T & C & C & $\mathrm{T}$ & G & $\mathrm{T}$ \\
\hline & m4-51 & cow (5), tick (2) & C & G & $\mathrm{T}$ & G & $A$ & $\mathrm{~T}$ & $\mathrm{~T}$ & C & $\mathrm{T}$ & C & $\mathrm{T}$ & A & C \\
\hline
\end{tabular}

Note: Anaplasma phagocytophilum $\mathrm{HZ}$ complete genome (NC_007797) was used as reference strain analogous to Silaghi et al. [23]

Nucleotide positions indicate the relative position to the genes:

a 1433 bp of rrsA 16S ribosomal RNA (Gene ID: 3930754 )

${ }^{b} 1653$ bp of groEL chaperonin groEL (Gene ID: 3930333)

' 1098 bp of APH 1361 major surface protein 2 (Gene ID: 3930710)

d 849 bp of msp 4 major surface protein 4 (Gene ID: 3930710)

${ }^{\mathrm{e}}$ Not official nomenclature; letters in parentheses are based on nomenclature in other publications $[17,23,25]$

but has been previously used by other workers [17, $23,25]$.

\section{5 rRNA gene sequences}

The amplification of the $16 S$ rRNA gene was successful in 29/30 previously selected samples and 5 different gene variants were found. From 21 tested samples of the heifers and the cow two variants here called "16S-20 $(\mathrm{W})$ " $(n=20)$ and "16S-22 (Y)" $(n=1)$ could be observed. The heifer without clinical signs had variant "16S-22 (Y)". In three roe deer samples two variants here called "16S-21 (X)" $(n=2)$ and "16S-19 (V)-like" $(n=1)$ could be observed. In engorged ticks three variants called "16S-20 (W)" ( $n=3)$, "16S-22 (Y)" $(n=1)$ and "16S-7 (I)" $(n=1)$ were found. All 29 tested partial $16 S$ rRNA gene sequences had $99.2-100 \%$ identity to each other.

\section{GroEL gene sequences}

Amplicons of the partial groEL gene could be obtained in only 13 cow samples and two different variants were observed: variant "g-15 $(\mathrm{N}) "(n=3)$ and variant "g-18 (X)" $(n=10)$. The identity between the partial groEL gene sequences was $99.6-100 \%$ among each other. Interestingly in no. 22 initially variant "g-
$18(\mathrm{X})$ " was detected while 4 month later variant "g$15(\mathrm{~N})$ " was observed in the same animal (Table 1).

\section{Msp2 gene sequences}

Analysis of the partial $m s p 2$ gene revealed amplicons in $12 / 30$ selected samples which could be analysed. In cow samples two variants " $\mathrm{m} 2-26$ " $(n=9)$ and " $\mathrm{m} 2-27$ " $(n=2)$ were detected and in roe deer variant " $\mathrm{m} 2-9(\mathrm{~J})$ " $(n=1)$. Variant " $\mathrm{m} 2-26$ " and " $\mathrm{m} 2-27$ " differ only in three nucleotide positions from each other, whereas " $\mathrm{m} 2-9(\mathrm{~J})$ " differs in further 45 nucleotide positions to " $\mathrm{m} 2-26$ " and " $\mathrm{m} 2-27$ " (Table 4). Therefore the $m s p 2$ gene sequences had an identity of $91.9-100 \%$ to each other.

\section{Msp4 gene sequences}

The amplification of the partial $m s p 4$ gene succeeded in 25 samples and showed four variants: variant " $\mathrm{m} 4-13$ $(n)$ " $(n=2)$, variant “m4-49" ( $n=13)$, variant "m4-50" $(n=3)$ and variant "m4-51" $(n=7)$. All four variants occurred in cattle samples and except for variant "m4-50" also in tick samples. The sequence identity between the partial msp4 gene sequences was $96.5-100 \%$ to each other. 


\section{Discussion}

\section{Clinical picture}

Prevalence of $A$. phagocytophilum infections of $27.6 \%$ confirmed by real-time PCR is higher in this herd than has been described before for other herds. Other workers found $17.1 \%$ positive by nested PCR (12/70 cows and heifers) [6] or $20 \%$ positive in a real-time PCR (4/20 cows and heifers) [11]. To our knowledge, a prevalence as high as $78.9 \%$ for natural $A$. phagocytophilum infections in naïve heifers confirmed by real-time PCR is described here for the first time. Observed clinical symptoms of TBF in this study (fever, reduced milk production, discharge from eyes and nose, lower limb oedema and stiff walking) match previous clinical case reports $[4,11,13,26,27]$ as well as observed symptoms after experimental infections $[5,7,28]$. Only heifers that went to the pastures for the first time showed typical clinical symptoms after infection. In contrast to other reports $[9,29,30]$ no abortions occurred in this study. Cattle pastured for more than one pasture period are susceptible for re-infections with $A$. phagocytophilum, but show no or very mild clinical symptoms [1,7]. This is in accordance to our observations with heifers nos. 22, 46, 57, 58 and 61 for which a re- or superinfection was demonstrated by PCR, but no clinical signs were observed (Table 1, Fig. 1). An explanation may be that immunity after an infection with $A$. phagocytophilum can last from 2 weeks up to more than 1 year and that these variants share common antigens [31]. In our study, fever was the first detectable sign of an infection with $A$. phagocytophilum. All real-time PCR-positive heifers except for no. 59 showed typical high fever; therefore measuring body temperature is a suitable initial examination for the detection of infected animals. In contrast, three heifers showed fever in the first week of pasturing without any laboratory evidence for an infection with A. phagocytophilum. The fever of no. 57 was very likely metritis-associated whereas the fever of the other two heifers (nos. 14, 59) could not be explained. There are possibly other (pasture associated) infections that might have caused high fever in this herd. The farm is located in the core region where Schmallenberg-Virus (SBV) was first found in late 2011 [32]. To rule out that fever not explained by $A$. phagocytophilum was caused by SBV, all blood samples were additionally screened for SBV by PCR and serology with the outcome that the complete herd seroconverted in weeks $38-40$ in 2011 [33]. By that time, only three heifers were still $A$. phagocytophilumnegative. It may be speculated that clinical TBF cases in endemic areas are associated with a pasture management that keeps heifers inside unexposed to ticks until they become cows and then show milk depression and other clinical signs of infection with A. phagocytophilum. Grazing of heifers on pastures would to a certain extend lead to natural A. phagocytophilum infection without the risk of milk depression, abortion or other clinical signs later in life time of these animals regardless of the particular strain involved in the secondary infection. We cannot rule out that the re-infections are indeed persistent infections, which would make cattle a suitable reservoir host for A. phagocytophilum, but we rather consider the infection short-lived. However, the finding that not a single animal was PCR-positive in the herd screening in January 2012 argues against a reservoir role of cattle.

\section{Cytological, serological, haematological and biochemical examination}

Reports of experimental infections of cattle with $A$. phagocytophilum reveal that morulae occur after 5-8 days post infection $[5,7]$. Thus, the first infections with $A$. phagocytophilum in this herd took place in the first days of pasturing. Maximum seroprevalence of $36.2 \%$ in July 2011 in this herd indicates a high level of endemicity in this area. Other workers describe higher seroprevalences with a maximum of $63 \%$ in September in Switzerland [6] or two peaks with a seroprevalence of $75 \%$ and $80 \%$ in June and November in France [11]. These differences are probably due to variations in vector activity depending on the climate. Prior to pasturing the herd was serologically negative. We assume that the serological situation of the herd must have been similar in the previous year, because of reported typical clinical signs of TBF and the first laboratory evidence for $A$. phagocytophilum in this herd in 2010 [8]. This might be due to a complete fading of antibodies between the pasture seasons and matches the half-live of bovine IgG of 1722 days [34]. New increases in antibody titers during the pasture season are probably due to re- or superinfections with identical or differing $A$. phagocytophilum variants. The phenomenon of undulating antibody titers during one season was already described by others but the possible involvement of different $A$. phagocytophilum strains was not investigated [7, 31, 35].

Most of the haematological findings match reports from clinical cases $[5,13,26]$ as well as cases after experimental infections $[4,7,28]$. The most important haematological finding is severe leucopenia that was also found in the present study. Thrombocytopenia and eosinopenia are often described in A. phagocytophilum infections [1], but they were not statistically significant in our results. To our knowledge, there is only one report about biochemical findings in cows after experimental infection with $A$. phagocytophilum [4] and it also shows a significant decrease in creatinine and bilirubin. This is 
the first report about a statistically significant decrease in albumin, $\gamma$-GT, GLDH, magnesium and calcium in naturally infected cattle. Due to the small number of animals in the statistical analysis the validity of these results remains to be proven.

\section{Environmental investigations}

In our study $100 \%$ of the roe deer $(n=3)$ were positive for A. phagocytophilum. Despite the small number of involved animals, this result matches prevalences of $A$. phagocytophilum found in roe deer in Germany with $94 \%$ and $98.9 \%$, respectively $[25,36]$. There is only one report about prevalences of $A$. phagocytophilum of wild boars in Germany with a prevalence of $12.5 \%$ [37], but other studies from eastern European countries also found quite low prevalences in wild boars between 2.7$12.0 \%$ [14]. Thus, the negative result of the wild boar in our study was not surprising. Prevalences of $A$. phagocytophilum in questing ticks from Germany range between $1.0-17.4 \%$ [14]. The detected prevalence of $1.7 \%$ in questing ticks observed in our study matches the results of other reports. In contrast reports with engorged ticks from roe deer show prevalences of A. phagocytophilum DNA of $86.1 \%$ (285/331, only adults) and $81 \%$ (245/301; adults, larvae and nymphs), respectively $[25,38]$. We found a much lower prevalence of $29.6 \%(8 / 27)$ in engorged ticks from roe deer. As the DNA amount in all samples was within one log level we assume the result is not a matter of DNA quality or quantity. Palomar et al. [39] found a prevalence of 30.5\% (61/200) in engorged $I$. ricinus from cows and Venclíková et al. [40] found a prevalence of $16.6 \%$ (33/199) in engorged I. ricinus from sheep. We found a similar prevalence of $18.9 \%(14 / 74)$ in engorged $I$. ricinus from cattle. However, it remains unclear whether engorged ticks were positive for $A$. phagocytophilum before the blood meal or if the positivity is a remnant of the current blood meal.

\section{Gene sequences}

Each of the PCRs used may have a different sensitivity and the amplicon lengths varies from $350 \mathrm{bp}$ to $893 \mathrm{bp}$. However both facts do not entirely explain why some of the loci could not be amplified (Table 1). Five different partial $16 S$ rRNA gene variants of A. phagocytophilum were detected. The main variant found in cattle was "16S-20 (W)". This variant was found in all heifers with clinical symptoms and in engorged ticks from cattle, but not in roe deer. This variant has previously been described in infected cattle in Switzerland and Turkey $[41,42]$, in sheep in Norway [28, 43], in chamois (Rupicapra rupicapra), mouflon (Ovis musimon) [17, 44] and ticks [45]. There is a repeating occurrence of variant "16S-20 (W)" in infected cattle independently from the geographical origin, therefore this variant seems to be important in causing clinical infections with A. phagocytophilum in cattle, at least in Switzerland and Germany.

Variant "16S-22 (Y)" was found in one heifer (no. 59) and in one engorged tick. Interestingly this heifer did not show any clinical signs despite daily monitoring. This variant has previously been described in goats [41], roe deer, mouflon in Austria [17], roe deer, mouflon, and fallow deer in central Germany [46], Swedish moose (Alces alces) [47], rodents in Florida [48] and ticks [45, 49].

Variant "16S-21 (X)" has previously been described in goats, roe deer, chamois $[17,41,44,50,51]$ and ticks [45]. In the USA this variant has often been found in white-tailed deer (Odocoileus virginianus) and is identical to the human apathogenic variant Ap-V1 [52].

Variant "16S-7 (I)" has previously been described in roe deer $[17,36]$ and variant "16S-19 (V-like)" has not been described before. Recent work demonstrated variant $\mathrm{X}$ and $\mathrm{I}$ in roe deer and mouflon in central Germany [46].

In cattle, we found two different partial groEL gene variants. Variant g-18 (X) has been previously found in cattle in France [53], sheep in Norway [28] and ticks in Spain [54] Variant g-15 (N) and the found partial $m s p 2$ gene variants have never been described before. The partial msp4 gene variant "m4-13 (n)" has been found previously in roe deer $[17,53]$. Variant "M4-51" has been previously described in cattle in France [53] and ticks in Norway [49]. Variants "M4-49" and "M4-50" have not been described before.

These different variants seem to be present throughout one season as they were found repeatedly indicating a stable circulation of different $A$. phagocytophilum strains in this area at least for one season (Table 1). Only one observed heifer (no. 59) did not show any clinical signs when first infected with $A$. phagocytophilum. It can be ruled out that clinical signs in this heifer have been overlooked, because of the daily measuring of body temperature over the whole pasture period. Interestingly no. 59 was the only heifer with $16 \mathrm{~S}-22$ (Y) and M4-13 (n) gene variants (Table 1) which might be apathogenic for cattle. This is supported by the fact that this $16 \mathrm{~S}$ rRNA gene and msp4 gene variants were previously found in roe deer in Austria [17]. Roe deer are likely a main reservoir host for A. phagocytophilum, but not for cattle-pathogenic variants $[2,55]$. Transmission of variants between cattle and roe deer can possibly occur due to a spillover effect [53].

This is the first report about re- and superinfections with various four locus variants of $A$. phagocytophilum in cattle during one grazing period. Animal no. 22 was infected with three different strains with different msp4 gene variants in May, July and October while no. 57 was infected with $A$. phagocytophilum having the same M449 gene variants in June and September 2011 (Table 1). 
This indicates that infection with A. phagocytophilum probably does not result in sterile immunity. Meanwhile many genetic variants have been described based on the genes used here or other genetic markers worldwide [2]. With the various re- and superinfections found, we postulate that this would happen to cattle in any other country where A. phagocytophilum is endemic. Although genetic heterogeneity had been described for cattle before [2], the genetic heterogeneity in the cattle samples described here was surprising. This heterogeneity may be even larger, as we investigated only four genetic markers. This is even more notable, because all samples were from a very small geographic region (less than $1 \mathrm{~km}^{2}$ ) during one pasture season and every cow in this study was born on this farm. Red deer is supposed to be a suitable reservoir host of $A$. phagocytophilum for infections of domestic ruminants, but not for humans, horses and dogs [56]. Interestingly, the red deer does not exist in the pasture area; their habitat starts approximately $20 \mathrm{~km}$ north from the farm. The pasture areas are regularly frequented by wild boars. Wild boars and hedgehogs were identified to be possible reservoir hosts for $A$. phagocytophilum for humans, horses and dogs and possibly also for sheep and cattle [2]. Single wild boars can cover distances of more than $100 \mathrm{~km}$ [57], so they might serve as a "bridging"-host from red deer to cattle in this area.

\section{Control and prevention}

Economic losses due to TBF in lactating cows may best be prevented by allowing first and second season grazing cattle to acquire at least partial immunity in endemic areas. Dry cows should be kept in stables though, as they show more severe clinical symptoms than lactating cows [4]. Furthermore, the risk of abortion due to infection with $A$. phagocytophilum is increased in the last trimester of pregnancy [29].

Avoiding pastures with typical tick habitats, by fencing out certain tick infested areas or by avoiding typical tick population peaks in May-June and September might be an option for those farms that cannot bring their heifers to pastures. However, even though this might reduce the tick burden, but will not protect completely from infections with tick-borne diseases.

Bayticol $^{\circ}$ is the only authorized repellent for cattle with long acting effect (3 weeks) against ticks on the German market. The results of the farmer's treatment indicate a relatively good effectiveness of flumethrin, but the number of treated animals in this study was too low to make a statement about the overall effectiveness of the drug. Stuen et al. [58] showed that Bayticol ${ }^{\circ}$ could reduce the tick burden in sheep but could not protect the animals from seroconversion. Bayticol ${ }^{\circ}$ has 8 days of withholding period on milk; therefore, it is not suitable for dairy herds.

\section{Conclusion}

In the observed dairy cattle herd we found a high prevalence of $A$. phagocytophilum-infections and clinical signs allowing a tentative diagnosis of TBF. Four locus sequence typing (16S rRNA, groEL, msp 2 and msp4) showed that several genetic variants sympatrically circulate in this small geographical region. Cows harbored other genetic variants than roe deer. This might be indicative for either distinct transmission cycles or host selection/restriction of particular A. phagocytophilum variants. Pathogenicity, host tropism and possible reservoir hosts of the detected genetic variants remain unclear and need to be further investigated.

\section{Additional files}

Additional file 1: Table S1. Primers used for the PCR amplifications and sequence analysis of Anaplasma phagocytophilum in this study. (DOC $33 \mathrm{~kb}$ )

Additional file 2: Figure S1. Overview of the herd seroprevalence during one season (based on the data shown in Table 2). First samples were taken in May shortly before the animals went to pasture. Despite two animals with a titre of 1:50 (dark asterisk), no measurable antibody titres were detected. This changed over the following months ( $x$-axis). The left $y$-axis shows the percentage of seropositive animals (blue, cows; green, heifers). Logarithmic titres are given on the right $y$-axis. Boxplots in gray display the median titre (black bars), upper and lower quartile and the upper wisker. Outliers (asterisks) were found in May and January. In January only two heifers had antibody titres of 1:100 and 1:200, while 10 further animals had a remaining antibody titre of 1:50 (darker asterisk). (TIFF $54 \mathrm{~kb}$ )

Additional file 3: Table S2. Accession numbers of gene variants of $A$. phagocytophilum in comparison with variants from GenBank. (DOC 42 kb)

\section{Abbreviations}

165 rRNA: 16 Svedberg ribosomal ribonucleic acid; GLDH: Glutamate dehydrogenase; groEL: Heat shock protein HSP60, also known as chaperonin 60; HGA: Human granulocytic anaplasmosis; IFAT: Indirect

immunofluorescence assay; msp2: Major surface protein 2; msp4: Major surface protein 4; SBV: Schmallenberg virus; SD: Standard diviation; TBF: Tickborne fever; $\gamma$-GT: $\gamma$-glutamyltransferase

\section{Acknowledgments}

The authors thank Claudia Thiel, Andrea Mihalkov (both Institute of Comparative Tropical Medicine and Parasitology, Faculty of Veterinary Medicine, LudwigMaximilians-University Munich), Ingrid Hartmann (Clinic for Ruminants, Faculty of Veterinary Medicine, Ludwig-Maximilians-University Munich), Dietlinde Woll and Carolin Oltersdorf (both Institute for Animal Hygiene and Veterinary Public Health, Faculty of Veterinary Medicine Universitiy of Leipzig) for their excellent technical assistance and the family of the owner of the cattle herd for their great cooperation. The work of CS and MP was done under the frame of EurNegVec COST Action TD1303.

\section{Funding}

Not applicable.

\section{Availability of data and materials}

Sequence data have already been deposited in GenBank under accession numbers KU587048-KU587126. Primer data and cycling conditions are found in the Additional file 1: Table S1. Fever curves for each individual cattle as well as detailed blood parameters over the course of the pasture season will be made available upon request. Extracted DNA of blood and environmental samples will be made available upon request in case there is leftover material. 


\section{Authors' contributions}

$\mathrm{CS}, \mathrm{MN}$ and MP designed the study, wrote the manuscript draft and did the genetic analyses of the Anaplasma phgacytophilum-positive samples. CSL did the statistical analyses, KGS and MN did the cytological, haematological and biochemical examinations of the blood samples. CS, MN and KP did the serology. MN did all the cattle and environmental sampling. All authors read and approved the final manuscript.

\section{Ethics approval and consent to participate}

Tick sampling does not need approval in North-Rhine-Westphalia. Game (three roe deer and one wild boar) were shot from licensed hunters during the hunting season according to the hunting law in Germany. Blood samples from cattle were taken as diagnostic samples in fever patients in order to detect tick-borne fever, Schmallenberg virus or other causes of illness and thus did not need an ethical approval.

\section{Consent for publication}

Not applicable.

\section{Competing interests}

The authors declare that they have no competing interests.

\section{Publisher's Note}

Springer Nature remains neutral with regard to jurisdictional claims in published maps and institutional affiliations.

\section{Author details}

'Comparative Tropical Medicine and Parasitology, Faculty of Veterinary Medicine, Ludwig-Maximilians-University Munich, Munich, Germany. ${ }^{2}$ Present Address: Federal Research Institute for Animal Health, Institute of Infectology, Friedrich-Loeffler-Institute, Riems, Germany. Institute for Animal Hygiene and Veterinary Public Health, Faculty of Veterinary Medicine, University of Leipzig, Leipzig, Germany. ${ }^{4}$ Clinic for Ruminants with Ambulatory and Herd Health Services at the Centre for Clinical Veterinary Medicine,

Ludwig-Maximilians-University Munich, Munich, Germany. ${ }^{5}$ Federal Research Institute for Animal Health, Institute of Epidemiology,

Friedrich-Loeffler-Institut, Riems, Germany.

\section{Received: 10 July 2017 Accepted: 4 December 2017}

\section{Published online: 08 January 2018}

\section{References}

1. Woldehiwet Z. The natural history of Anaplasma phagocytophilum. Vet Parasitol. 2010;167:108-22.

2. Huhn C, Winter C, Wolfberger T, Wüppenhorst N, Strasek Smrdel K, Skuballa J, et al. Analysis of the population structure of Anaplasma phagocytophilum using multilocus sequence typing. PLoS One. 2014;9:e93725.

3. Woldehiwet Z. Anaplasma phagocytophilum in ruminants in Europe. Ann New York Acad Sci. 2006;1078:446-60.

4. Pusterla N, Braun U. Clinical findings in cows after experimental infection with Ehrlichia phagocytophila. J Veterinary Med Ser B. 1997;44:385-90.

5. Pusterla N, Huder J, Wolfensberger C, Braun U, Lutz H. Laboratory findings in cows after experimental infection with Ehrlichia phagocytophila. Clin Diagnic Lab Immunol. 1997;4:643-7.

6. Pusterla N, Pusterla JB, Braun U, Lutz H. Serological, hematologic, and PCR studies of cattle in an area of Switzerland in which tick-borne fever (caused by Ehrlichia phagocytophila) is endemic. Clin Diagn Lab Immunol. 1998;5: 325-7.

7. Tuomi J. Experimental studies on bovine tick-borne fever. 1. Clinical and haematological data, some properties of the causative agent, and homologous immunity. Acta Pathol Microbiol Scand. 1967;70:429-45.

8. Nieder M, Silaghi C, Hamel D, Pfister K, Schmäschke R, Pfeffer M. Tick-borne fever caused by Anaplasma phagocytophilum in Germany: first laboratory confirmed case in a dairy cattle herd. Tieraerztl Praxis Ausgabe G Grosstiere Nutztiere. 2012;40:101-6.

9. Cranwell MP, Gibbons JA. Tick-borne fever in a dairy herd. Vet Rec. 1986; 119:531-2.

10. Hudson JR. The recognition of tick-borne fever as a disease of cattle. Brit Vet J. 1950;106:3-17
11. Laloy E, Petit E, Boulouis HJ, Gandoin C, Bouillin C, Gounot G, et al. Dynamics of natural infection by Anaplasma phagocytophilum in a dairy cattle herd in Brittany, France. Clin Microbiol Infect. 2009;15:24-5.

12. Liz JS. Ehrlichia phagocytophila: aspects épidémiologiques, hématologiques et sérologiques de l'ínfection chez les bovins en Suisse. (dissertation). Neuchâtel: University of Neuchâtel; 1994.

13. Streit M. Zur Klinik, Hämatologie und Epidemiologie der Ehrlichiose (Weidefieber) beim Rind (dissertation). Bern: University of Bern; 1993.

14. Stuen S, Granquist EG, Silaghi C. Anaplasma phagocytophilum - a widespread multi-host pathogen with highly adaptive strategies. Front Cell Infect Microbiol. 2013;3:31.

15. Hillyard PD. Ticks of North-West Europe. Keys and notes for identification of the species. Shrewsbury: Published for the Linnean Society of London and the Estuarine and Coastal Sciences Association by Field Studies Council (Synopses of the British fauna, new ser., no. 52); 1996.

16. Courtney J, Kostelnik L, Zeidner NS, Massung RF. Multiplex real-time PCR for detection of Anaplasma phagocytophilum and Borrelia burgdorferi. J Clin Microbiol. 2004;42:3164-8.

17. Silaghi C, Hamel D, Thiel C, Pfister K, Passos LMF, Rehbein S. Genetic variants of Anaplasma phagocytophilum in wild caprine and cervid ungulates from the alps in Tyrol, Austria. Vector-Borne Zoonotic Dis. 2011;11:355-62.

18. Massung RF, Slater K, Owens JH, Nicholson WL, Mather TN, Solberg VB, Olson JG. Nested PCR assay for detection of granulocytic ehrlichiae. J Clin Microbiol. 1998;36:1090-5.

19. Alberti A, Zobba R, Chessa B, Addis MF, Sparagano O, Pinna Parpaglia ML, et al. Equine and canine Anaplasma phagocytophilum strains isolated on the island of Sardinia (Italy) are phylogenetically related to pathogenic strains from the United States. Appl Environ Microbiol. 2005;71:6418-22.

20. Lin Q, Rikihisa Y, Massung RF, Woldehiwet Z, Falco RC. Polymorphism and transcription at the $p 44-1 / p 44-18$ genomic locus in Anaplasma phagocytophilum strains from diverse geographic regions. Infect Immun. 2004;72:5574-81.

21. Bown K, Lambin X, Ogden NH, Petrovec M, Shaw SE, Woldehiwet Z, Birtles RJ. High-resolution genetic fingerprinting of European strains of Anaplasma phagocytophilum by use of multilocus variable-number tandem-repeat analysis. J Clin Microbiol. 2007:45:1771-6.

22. de la Fuente J, Massung RF, Wong SJ, Chu FK, Lutz H, et al. Sequence analysis of the msp4 gene of Anaplasma phagocytophilum strains. J Clin Microbiol. 2005;43:1309-17.

23. Silaghi C, Liebisch G, Pfister K. Genetic variants of Anaplasma phagocytophilum from 14 equine granulocytic anaplasmosis cases. Parasit Vectors. 2011:4:161.

24. Chenna R. Multiple sequence alignment with the Clustal series of programs. Nucl Acids Res. 2003;31:3497-500

25. Overzier E, Pfister K, Herb I, Mahling M, Böck G, Silaghi C. Detection of tickborne pathogens in roe deer (Capreolus capreolus), in questing ticks (Ixodes ricinus), and in ticks infesting roe deer in southern Germany. Ticks Tickborne Dis. 2013;4:320-8.

26. Pfister K, Roesti A, Boss PH, Balsinger B. Ehrlichia phagocytophila als Erreger des Weidefiebers im Berner Oberland. Schweizer Arch Tierheilk. 1987;129: $343-7$.

27. Joncour PG. Anaplasma phagocytophilum, agent de l'ehrlichiose granulocytaire bovine (EGB) et d'avortements chez les bovins, propostion de protocole d'aide au diagnostic. Bulletin de GTV. 2006;35:95-104.

28. Stuen S, Bergstrom K, Petrovec M, Van de Pol I, Schouls LM. Differences in clinical manifestations and hematological and serological responses after experimental infection with genetic variants of Anaplasma phagocytophilum in sheep. Clin Vaccine Immunol. 2003;10:692-5.

29. Wilson JC. Tick-borne fever as a cause of abortion and stillbirths in cattle. Vet Rec. 1964;76:1081-4.

30. Dugat T, Hacaine D, Durand B, Lagrée AC, Haddad N, Boulouis HJ. Short report: identification of a potential marker of Anaplasma phagocytophilum associated with cattle abortion. Transbound Emerg Dis. 2017;64:e1-3.

31. Woldehiwet Z, Scott GR. Immunological studies on tick-borne fever in sheep. J Comp Pathol. 1982;92:457-67.

32. Hoffmann B, Scheuch $M$, Höper $D$, Jungblut $R$, Holsteg $M$, Schirrmeier $H$, et al. Novel Orthobunyavirus in cattle, Europe, 2011. Emerg Infect Dis. 2012; 18:469-72.

33. Wernike K, Silaghi C, Nieder M, Pfeffer M, Beer M. Dynamics of Schmallenberg virus infection within a cattle herd in Germany, 2011. Epidemiol Infect. 2014;142:1501-4. 
34. Tizard I. Veterinary immunology. 9th ed. Philadelphia: Saunders; 2013.

35. Foggie A. Studies on the infectious agent of tick-borne fever in sheep. J Pathol Bacteriol. 1951;63:1-15.

36. Scharf W, Schauer S, Freyburger F, Petrovec M, Schaarschmidt-Kiener D, Liebisch G. Distinct host species correlate with Anaplasma phagocytophilum ankA gene clusters. J Clin Microbiol. 2011:49:790-6.

37. Silaghi C, Pfister K, Overzier E. Molecular investigation for bacterial and protozoan tick-borne pathogens in wild boars (Sus scrofa) from southern Germany. Vector-Borne Zoonotic Dis. 2014;14:371-3.

38. Jahfari $S$, Coipan EC, Fonville $M$, van Leeuwen AD, Hengeveld P, Heylen D, Heyman P, van Maanen C, Butler CM, Földvarí G, Szekeres S, van Duijvendijk G, Tack W, Rijks JM, van der Giessen J, Takken W, van Wieren SE, Takumi K, Sprong H. Circulation of four Anaplasma phagocytophilum ecotypes in Europe. Parasit \& Vectors. 2014;7:365.

39. Palomar AM, Gracía-Álvarez L, Santibánez S, Portillo A, Oteo JA. Detection of tick-borne 'Candidatus Neoehrlichia mikurensis' and Anaplasma phagocytophilum in Spain in 2013. Parasit \& Vectors. 2014;7:57.

40. Venclíková K, Mendel J, Betásová L, Blazejová H, Jedlickova P, Straková P, et al. Neglected tick-borne pathogens in the Czech Republic, 2011-2014. Ticks Tick-borne Dis. 2016;7:107-12.

41. Silaghi C, Scheuerle MC, Friche Passos LM, Thiel C, Pfister K. PCR detection of Anaplasma phagocytophilum in goat flocks in an area endemic for tickborne fever in Switzerland. Parasite. 2011;18:57-62.

42. Aktas M, Özübek S. Bovine anaplasmosis in Turkey. First laboratory confirmed clinical cases caused by Anaplasma phagocytophilum. Vet Microbiol. 2015;178:246-51.

43. Stuen S, Van De Pol I, Bergström K, Schouls LM. Identification of Anaplasma phagocytophila (formerly Ehrlichia phagocytophila) variants in blood from sheep in Norway. J Clin Microbiol. 2002;40:3192-7.

44. Zeman P, Pecha M. Segregation of genetic variants of Anaplasma phagocytophilum circulating among wild ruminants within a bohemian forest (Czech Republic). Internat J Med Microbiol. 2008;298:203-10.

45. von Loewenich FD, Baumgarten BU, Schröppel K, Geißdörfer W, Röllinghoff $M$, et al. High diversity of ankA sequences of Anaplasma phagocytophilum among Ixodes ricinus ticks in Germany. J Clin Microbiol. 2003;41:5033-40.

46. Kauffmann M, Rehbein S, Hamel D, Lutz W, Heddergott M, Pfister K, Silaghi C. Anaplasma phagocytophilum and Babesia spp. in roe deer (Capreolus capreolus), fallow deer (Dama dama) and mouflon (Ovis musimon) in Germany. Mol Cell Probes. 2017;31:46-54.

47. Malmsten J, Widén DG, Rydevik G, Yon L, Hutchings MR, Thulin CG, Söderquist L, Aspan A, Suen S, Dalin AM. Temporal and spatial variation in Anaplasma phagocytophilum infection in Swedish moose (Alces alces). Epidemiol Infect. 2014;142:1205-13.

48. Clark KL. Anaplasma phagocytophilum in small mammals and ticks in northeast Florida. J Vector Ecol. 2012;37:262-8.

49. Paulauskas A, Radzijevskaja J, Rosef O. Molecular detection and characterization of Anaplasma phagocytophilum strains. Comp Immunol Microbiol Infect Dis. 2012;35:187-95.

50. Liz JS, Sumner JW, Pfister K, Brossard M. PCR detection and serological evidence of granulocytic ehrlichial infection in roe deer (Capreolus capreolus) and chamois (Rupicapra rupicapra). J Clin Microbiol. 2002;40: 892-7.

51. Petrovec M, Bidovec A, Sumner JW, Nicholson WL, Childs JE, Avsic-Zupanc T. Infection with Anaplasma phagocytophila in cervids from Slovenia: evidence of two genotypic lineages. Wien Klin Wochenschr. 2002;114:641-7.

52. Massung RF, Mauel MJ, Owens JH, Allan N, Courtney JW, Stafford KC 3rd, Mather TN. Genetic variants of Ehrlichia phagocytophila, Rhode Island and Connecticut. Emerg Infect Dis. 2002;8:467-72.

53. Chastagner A, Dugat $T$, Vourc'h $G$, Verheyen $H$, Legrand $L$, Bachy $V$, et al. Multilocus sequence analysis of Anaplasma phagocytophilum reveals three distinct lineages with different host ranges in clinically ill French cattle. Vet Res. 2014:45:114

54. Portillo A, Pérez-Martìnez L, Santibánez S, Santibánez P, Palomar AM, Oteo JA. Anaplasma spp. in wild mammals and Ixodes ricinus from the north of Spain. Vector-Borne and Zoonotic Dis. 2011;11:3-8.

55. Dugat T, Chastagner A, Lagrée AC, Petit E, Durand B, Thierry S, et al. A new multiple-locus variable-number tandem repeat analysis reveals different clusters for Anaplasma phagocytophilum circulating in domestic and wild ruminants. Parasit \& Vectors. 2014;7:439.

56. Dugat T, Loux V, Marthey S, Moroldo M, Lagrée AC, Boulouis HJ, et al. Comparative genomics of first available bovine Anaplasma phagocytophilum genome obtained with targeted sequence capture. BMC Genomics. 2014;15:973.

57. Jerina K, Pokorny B, Stergar M. First evidence of long-distance dispersal of adult female wild boar (Sus scrofa) with piglets. Europ J Wildl Res. 2014:4:1-4.

58. Stuen S, Enemark J, Artursson K, Nielson B. Prophylactic treatment with flumethrin, a pyrethroid (Bayticol $\left({ }^{\oplus}\right)$, Bayer), against Anaplasma phagocytophilum infection in lambs. Acta Vetarinaria Scandinavica. 2012;54:31.

\section{Submit your next manuscript to BioMed Central and we will help you at every step:}

- We accept pre-submission inquiries

- Our selector tool helps you to find the most relevant journal

- We provide round the clock customer support

- Convenient online submission

- Thorough peer review

- Inclusion in PubMed and all major indexing services

- Maximum visibility for your research

Submit your manuscript at www.biomedcentral.com/submit
Biomed Central 